\title{
Mesenteric lymphadenopathy in children with chronic abdominal pain
}

\author{
Vaisakh Sambasivan Balakrishnan ${ }^{1}$, Shrikiran Aroor ${ }^{2}$, *Sandeep Kumar ${ }^{3}$, Pushpa Gurudas Kini², \\ Anjana Saseendran ${ }^{4}$
}

Sri Lanka Journal of Child Health, 2018; 47(4): 348-353

\begin{abstract}
Background: Mesenteric lymphadenopathy is a common finding described by abdominal ultrasonography in children.
\end{abstract}

Objective: To estimate incidence and significance of mesenteric lymphadenopathy (MLN) in children with chronic abdominal pain (CAP) as compared to healthy children.

Method: A prospective observational study was conducted in the paediatric department of a tertiary care hospital. Cases included children of age group 5-15 years with CAP who were subjected to abdominal ultrasonography during the study period. Controls included children in whom abdominal sonography was performed for reasons other than abdominal pain. Descriptive statistics were used for the analysis of baseline characteristics of the study group. For the variables following normal distribution curve, mean and standard deviation were computed. The presence of enlarged nodes, their location, size and other significant findings were recorded. Pearson's Chi-square test was used to analyse categorical variables between groups.

Results: Three hundred and eighteen children were enrolled in the study. After excluding those who did not meet the criteria, the final study population included 110 cases and 138 controls. CAP was almost equal in both sexes with male: female ratio of 1:1.07. Mesenteric lymph nodes were detected by ultrasonography in $84(72.1 \%)$ cases and in 41 (13.4\%) controls. Significant MLN ( $\geq 5 \mathrm{~mm}$ short axis or $>10 \mathrm{~mm}$ long axis) was present in $62(56.4 \%)$ of 110 children with CAP, in contrast to $16(11.6 \%)$ of 138 controls $(p<0.001)$. Most common location of the nodes was in the right iliac fossa $(79 \%)$ followed by peri-umbilical location $(77.4 \%)$.

\footnotetext{
${ }_{1}^{1}$ Junior Resident, ${ }^{2}$ Professor, ${ }^{3}$ Assistant Professor, ${ }^{4}$ Senior Resident, Kasturba Medical College, Manipal Academy of Higher Education, Manipal,India

*Correspondence: bksandydoc@gmail.com

(Received on 02 March 2018: Accepted after revision on 20 April 2018)

The authors declare that there are no conflicts of interest

Personal funding was used for the project.

Open Access Article published under the Creative
}

Commons Attribution CC-BY CC (P) License
Conclusion: MLN, with lymph nodes more than $5 \mathrm{~mm}$ on their short axis, is a significant finding in children presenting with CAP.

\section{DOI: http://dx.doi.org/10.4038/sljch.v47i4.8598}

(Key words: Chronic abdominal pain, recurrent abdominal pain, mesenteric lymphadenopathy)

\section{Introduction}

In developed countries, chronic abdominal pain (CAP) is a complaint of $10-12 \%$ school children ${ }^{1}$. However, an organic cause is found only in 5-10\% of children with $\mathrm{CAP}^{2}$. There are very few studies that mention the prevalence and significance of mesenteric lymphadenopathy (MLN) in $\mathrm{CAP}^{3}$.

\section{Objective}

To estimate the incidence and significance of MLN in children with CAP as compared to healthy children.

\section{Method}

A prospective, single centre study was conducted in the paediatric department of Kasturba Medical College, Manipal, from October 2015 to July 2017, a period of 1 year and 9 months. Children aged 515 years, presenting with CAP, who were subjected to abdominal ultrasonography, were included as cases. Children who were subjected to abdominal sonography for reasons other than abdominal pain were included in the control group. Children with known organic causes for CAP (pancreatitis, dysmenorrhoea, abdominal TB, renal calculi etc.) were excluded from cases. Children with known cause for MLN e.g. gastroenteritis, malignancy, abdominal tuberculosis, rheumatic disorders etc. were excluded from cases as well as from controls. The study protocol was approved by the Institutional Ethics Committee. (IEC No. 641/2015). Written informed consent was obtained from the parents before inclusion in the study.

Data collected from history, physical examination and abdominal ultrasonography were recorded in a proforma designed for the study. Ultrasonography was performed by 2 experienced radiologists using Epiq-5G and Affiniti-50G units (Philips health care) with $8 \mathrm{MHz}$ convex-array transducer and 12 $\mathrm{MHz}$ linear transducer. The presence of enlarged nodes, their location, size and other significant findings were recorded. Each lymph node was measured in two dimensions (short axis and long 
axis). A size of more than $5 \mathrm{~mm}$ in short axis or more than $10 \mathrm{~mm}$ in the long axis was considered significant. Basic investigations were done according to case merit and the details were included.

The study data was processed using the Statistical Package for the Social Sciences (SPSS) V21.0. Descriptive statistics were used for the analysis of baseline characteristics of study group. For the variables following normal distribution curve, mean and standard deviation were computed. Pearson's Chi-square test was used in the analysis of categorical variables between groups. Significance was assessed at 5\% level using non parametric 2 tailed test. A $p$-value of $<0.05$ was considered statistically significant.

\section{Results}

A total of 318 children were enrolled in the study, which included 149 children with CAP (cases) and 169 controls. Among the 149 cases with CAP, 39 were excluded whilst 31 subjects were excluded from the control group. Thus, the final study population included 110 cases and 138 controls (Figure 1).

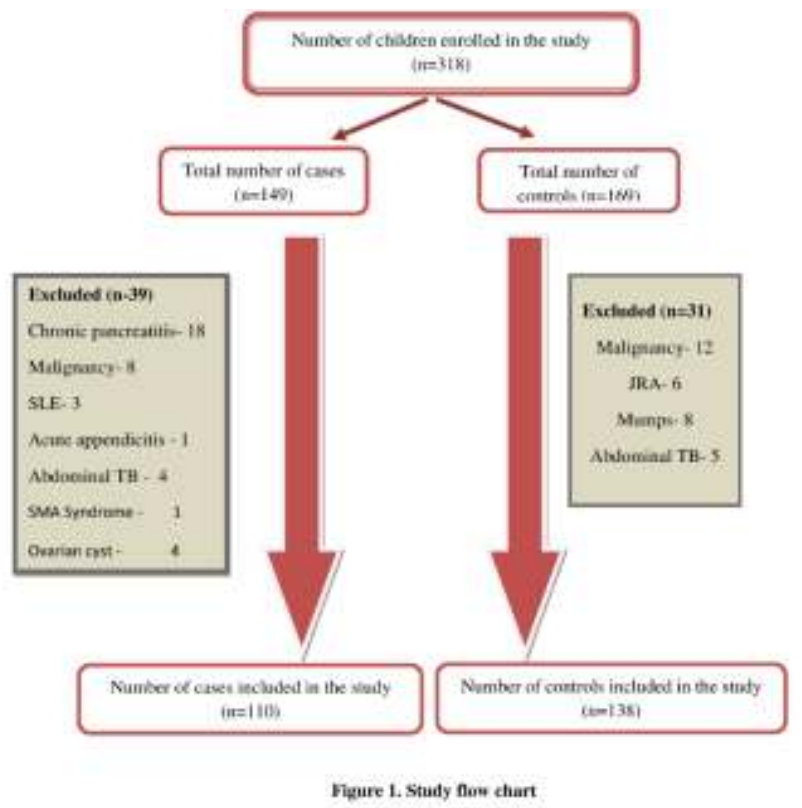

Of the 138 controls, 46 had congenital anomalies and genetic syndromes where abdominal sonography was done to rule out renal/ gastrointestinal malformations, 42 had renal disorders, 37 had hepatic disorders, 9 had pyrexia of unknown origin and 4 had miscellaneous disorders. CAP was almost equal in both sexes with a male: female ratio of 1:1.07. Mean age of the study group was $9.13 \pm 3.3$ years ranging from $5-15$ years. In the present study there were $73(66.3 \%)$ children aged

from 5 to 10 years and $37(33.7 \%)$ children aged from 10-15 years. Higher frequency of CAP was observed in the younger age group. Mean weight of all children with CAP was $24.34 \pm 9.8 \mathrm{~kg}$ and control was $26.79 \pm 12.65 \mathrm{~kg}$. Mean height of all the cases was $126.05 \pm 17.9 \mathrm{~cm}$ and controls was $127.25 \pm$ $22.77 \mathrm{~cm}$. Out of the 110 cases, $33(30 \%)$ and out of the 138 controls $33(23.9 \%)$ were undernourished with BMI $<3$ rd centile (Table 1).

Table 1: Baseline demographic characteristics of the study group

\begin{tabular}{|l|c|c|}
\hline \multicolumn{1}{|c|}{ Variable } & Cases $(\boldsymbol{n}=110)$ & Controls $(\boldsymbol{n}=138)$ \\
\hline Sex & & $79(57.2 \%)$ \\
Male $(n=132)$ & $53(48.1 \%)$ & $59(42.8 \%)$ \\
Female $(n=116)$ & $57(51.9 \%)$ & \\
\hline Age (years) & $73(66.3 \%)$ & $53(60.1 \%)$ \\
$5-10(n=156)$ & $37(33.7 \%)$ & $55(39.9 \%)$ \\
$10-15(n=92)$ & 33 & 33 \\
\hline Body mass index $\left(\mathrm{kg} / \mathrm{m}^{2}\right)$ & 77 & 105 \\
$<3$ rd centile $(n=66)$ & $24.34 \pm 9.88$ & $26.79 \pm 12.65$ \\
$>$ 3rd centile $(n=182)$ & $126.05 \pm 17.9$ & $127.25 \pm 22.77$ \\
\hline Weight $(\mathrm{kg})($ mean $\pm \mathrm{SD})$ & & \\
\hline Height $(\mathrm{cm})($ mean $\pm \mathrm{SD})$ & & \\
\hline
\end{tabular}


The median duration of abdominal pain was 4 months with the $75^{\text {th }}$ and $25^{\text {th }}$ IQR being 7 and 3 months respectively. When duration was categorized, it was observed that $81(73.6 \%)$ of the children had duration of pain between 3-6 months. Vomiting, fever and constipation were the main symptoms other than abdominal pain. (Table 2)

Table 2: Symptoms and signs in children with chronic abdominal pain $(n=110)$

\begin{tabular}{|l|c|}
\hline \multicolumn{1}{|c|}{ Variable } & Number (\%) \\
\hline Vomiting & $27(24.5)$ \\
\hline Constipation & $11(10.0)$ \\
\hline Fever & $11(10.0)$ \\
\hline Pallor & $28(25.5)$ \\
\hline Abdominal tenderness & $18(16.3)$ \\
\hline Hepatomegaly & $08(07.3)$ \\
\hline
\end{tabular}

On physical examination, the most common finding was pallor. Out of 110 children with CAP only $16.3 \%$ had abdominal tenderness most commonly in the periumbilical region and right iliac fossa. Complete haemogram was done in all 110 cases. Eosinophilia was present in $40 \%$, anaemia in $22.7 \%$, leucocytosis in $22.9 \%$ and elevated erythrocyte sedimentation rate in $14.4 \%$.

On ultrasonography (USG) MLN was detected in $76.3 \%$ of cases and in $29.7 \%$ of controls. Significant MLN ( $\geq 5 \mathrm{~mm}$ short axis) was present in $56.4 \%$ of children with CAP, in contrast to $11.6 \%$ of controls. Difference between the two groups analysed by Pearson's Chi square test was statistically significant (Table 3 ).

Table 3: Division of study group with reference to mesenteric lymph nodes in abdominal ultrasonography

\begin{tabular}{|c|c|c|c|}
\hline Mesenteric lymph nodes & $\begin{array}{c}\text { Cases }(n=110) \\
\text { Number }(\%)\end{array}$ & $\begin{array}{c}\text { Controls }(n=138) \\
\text { Number }(\%)\end{array}$ & $p$ value* \\
\hline Visualised $(n=125)$ & $84(76.3)$ & $41(29.7)$ & \multirow[b]{2}{*}{$<0.001$} \\
\hline Not visualised $(n=123)$ & $26(23.7)$ & $97(70.3)$ & \\
\hline Significant MLN $\geq 5 \mathrm{~mm}(n=78)$ & $62(56.4)$ & $16(11.6)$ & $<0.001$ \\
\hline
\end{tabular}

"Pearson's Chi square test

In the present study, MLN was more common among girls $(58 \%)$ with CAP. MLN among controls was more common in boys $(87.5 \%)$. Mean age of children among 62 cases with MLN was 8.4 \pm 3.1 years ranging from $5-15$ years. Mean age of children among 16 controls with MLN was $10.4 \pm$
3.6 years ranging from 5-15 years. No significant correlation of age was observed with MLN in this study $(\mathrm{r}=-0.314, \mathrm{p}=0.08$ (NS). Most common location of the nodes was in the right iliac fossa (RIF) region $(79 \%)$ followed by peri-umbilical location (77.4\%) (Table 4).

Table 4: Mesenteric lymphadenopathy based on location in ultrasonography of abdomen

\begin{tabular}{|l|c|c|}
\hline \multicolumn{1}{|c|}{ Site } & Cases $(\boldsymbol{n}=\mathbf{6 2})$ & Controls $(\boldsymbol{n}=\mathbf{1 6})$ \\
\hline Right iliac fossa (RIF) & 14 & 05 \\
\hline Peri-umbilical & 13 & 02 \\
\hline Peri-umbilical + RIF & 24 & 06 \\
\hline Epigastric + Peri-umbilical + RIF + Left iliac fossa (LIF) & 07 & 01 \\
\hline Peri-umbilical + RIF + LIF & 04 & 02 \\
\hline
\end{tabular}

\section{Discussion}

Recurrent abdominal pain (RAP) was described as a symptom complex by a British paediatrician John Apley and he defined it as "pain that waxes and wanes, occurring at least 3 times over a period longer than 3 months and severe enough to affect a child's activities"4. The American Academy of Paediatrics (AAP) Subcommittee on Chronic Abdominal Pain 2005 replaced the term RAP with CAP and defined the latter as "long-lasting intermittent or constant abdominal pain that is either functional or organic". Abdominal pain lasting for more than 1-2 months is considered chronic $^{5}$. Both RAP and CAP are being used interchangeably in clinical practice. However,
CAP is currently the preferred term as it encompasses RAP as well.

CAP is common among school children and young adolescents with prevalence ranging from 0.5 to $19 \%{ }^{6-9}$. Boey et al. reported a prevalence of CAP of $10.2 \%$ among Malaysian school children ${ }^{6,7}$. Two age peaks are often seen; one at 4-6 years and the other at 7-12 years ${ }^{8-10}$. Incidence is uncommon in children below 5 years and those above 15 years of age. In our study, higher frequency of CAP was observed in the age group of 5-10 years. Both boys and girls were equally affected in our study, though many studies have shown female preponderance ${ }^{8,9}$. Most of the studies have reported that only $10 \%$ cases of CAP have an organic pathology. Studies 
done in India have reported intestinal parasitic infection as one of the most important cause of $\mathrm{CAP}^{10}$. Gastroesophageal reflux disease (GERD) and constipation are the commonest causes of CAP in the developed countries ${ }^{1-15}$. An association between $\mathrm{H}$. pylori and CAP has been postulated, but is controversial. ${ }^{14}$ Studies have shown the presence of social and family stressors being associated with CAP. Some of the stressors include parental separation, domestic violence, school issues etc. ${ }^{11,13}$. As per ROME IV criteria, the term FGID (Functional gastrointestinal disorders) was replaced by the new terminology 'disorders of gutbrain interaction'- "a group of disorders classified by GI symptoms related to any combination of motility disturbances, visceral hypersensitivity, altered mucosal and immune function, gut microbiota, and/or central nervous system processing" $"$.

Abdominal ultrasonography is an important diagnostic tool performed to rule out an underlying organic abnormality. MLN is the commonest ultrasonographic finding in children with CAP, but its significance is rarely mentioned in the literature. Radiologically, MLN is used to describe the presence of 3 or more lymph nodes of size greater than $5 \mathrm{~mm}$ in its short axis ${ }^{17-19}$. MLN is called primary, when there is no other ultrasonographically identified abnormality and secondary, when an associated pathology is detected $^{19}$. A short axis of $<5 \mathrm{~mm}$ is considered insignificant ${ }^{20}$. MLN is commonly reported in children with acute abdominal pain and a few researchers have reported the significance of MLN in CAP as well ${ }^{17-20}$.

MLN was believed to be associated with acute appendicitis, lymphoma and intussusception ${ }^{21}$. Common aetiologies for MLN include viral infections, mainly adenovirus, Crohn's disease, gastroenteritis, HIV and Yersinia entercolitica ${ }^{22-24}$. Significant MLN is defined as a size of more than $5 \mathrm{~mm}$ in short axis (more than $10 \mathrm{~mm}$ in the long axis $)^{23,24}$. Similar to our study, a few studies have reported right lower quadrant of abdomen as the common site of location of MLN followed by the periumbilical region ${ }^{22-24}$.

This is a single centre prospective case control study to determine the presence and significance of mesenteric lymphadenopathy in children with CAP. This study showed that MLN is a common finding in children with CAP compared to asymptomatic children. Clinically significant MLN i.e. lymph nodes $>5 \mathrm{~mm}$ in short axis was significantly associated with chronic abdominal pain. Comprehensive laboratory investigations targeted to explore the aetiology of MLN were not performed in this study. We did not perform long- term follow-up of the subjects which would be useful to evaluate the natural history of MLN. These are limitations of this study. Abdominal ultrasonography is a useful tool in the evaluation of CAP to rule out organic causes. When MLN is the only finding in abdominal ultrasonography, parents can be reassured regarding the benign nature of this finding and possible good prognosis.

\section{Conclusions}

MLN, with lymph nodes more than $5 \mathrm{~mm}$ on their short axis, is a significant finding in children presenting with CAP.

\section{References}

1. Huang RC, Plamer LJ, Forbes DA. Prevalence and pattern of childhood abdominal pain in an Australian general practice. Journal of Paediatrics and Child Health 2000; 36: 349-53. https://doi.org/10.1046/j.14401754.2000.0 0513.x

PMid: 10940169

2. Apley J. The child with abdominal pain. $2^{\text {nd }}$ edition. Blackwell Scientific Publications, Oxford 1975.p. 13-6; 24-25; 29.

PMid: 1117020

3. Vayner N, Coret A, Polliack G, et al. Mesenteric lymphadenopathy in children examined by US for chronic and/or recurrent abdominal pain. Pediatric Radiology 2003; 33: 864-7. https://doi.org/10.1007/s00247-003-09857

PMid: 13679999

4. Apley J, Nash N. Recurrent abdominal pain: a field survey of 1000 school children. Archives of Disease in Childhood 1958; 33:165-70. https://doi.org/10.1136/adc.33.168.165 PMid: 13534750 PMCid: PMC2012205 $\mathrm{S}$

5. American Academy of Pediatrics Subcommittee on Chronic Abdominal Pain. Chronic abdominal pain in children. Pediatrics 2005; 115: 812-5. https://doi.org/10.1542/peds.2004-2497 PMid: 15741394

6. Boey CC, Yap S, Goh KL. The prevalence of recurrent abdominal pain in 11-16 yearold Malaysian school children. Journal of Paediatrics and Child Health 2000; 36: 114-6. 
https://doi.org/10.1046/j.14401754.2000.0

0465.x

PMid: 10760006

7. Boey CC, Goh KL. Predictors of recurrent abdominal pain among 9 to 15 year-old urban school-children in Malaysia. Acta Paediatrica 2001; 90: 353-5.

https://doi.org/10.1111/j.16512227.2001.t b00318.x

8. Rasul $\mathrm{CH}$, Khan MAD. Recurrent abdominal pain in school children in Bangladesh. Journal of the Ceylon College of Physicians 2000; 33: 110-4.

9. Devanarayana NM, de Silva DGH, de Silva HJ. Recurrent abdominal pain syndrome in a cohort of Sri Lankan children and adolescents. Journal of Tropical Pediatrics 2008; 54: 178-83.

https://doi.org/10.1093/tropej/fmm114

PMid: 18204085

10. Devanarayana NM, Rajindrajith S, De Silva HJ. Recurrent abdominal pain in children. Indian Pediatrics 2009; 46(5): 389-99.

PMid: 19478352

11. Chitkara DK, Rawat DJ, Talley NJ. The epidemiology of childhood recurrent abdominal pain in western countries: a systematic review. American Journal of Gastroenterology 2005; 100: 1868-75. https://doi.org/10.1111/j.15720241.2005.4 1893.x

PMid: 16086724

12. Stordal K, Nygaard EA, Bentsen B. Organic abnormalities in recurrent abdominal pain in children. Acta Paediatrica 2001; 90: 1-5. https://doi.org/10.1111/j.16512227.2001.t b02426.x

13. Buch NA, Ahmad SM, Ahmad SZ, Ali SW, Charoo BA, Hussan MU. Recurrent abdominal pain in children. Indian Pediatrics 2002; 39: 830-4.

PMid: 12368527

14. Das BK, Kakkar S, Dixit VK, Kumar M, Nath G, Mishra OP. Helicobacter pylori infection and recurrent abdominal pain in children. Journal of Tropical Pediatrics 2003; 49: 250-2. https://doi.org/10.1093/tropej/49.4.250

PMid: 12929890

15. Eidlitz-Markus T, Mimouni M, Zeharia A, et al. Occult constipation: a common cause of recurrent abdominal pain in childhood. Israel Medical Association Journal 2004; 6(11): 677-80.

PMid: 15562805

16. Drossman DA, Hasler WL. Rome IVfunctional GI disorders: disorders of gutbrain interaction. Gastroenterology 2016; 150: $1257-61$.

https://doi.org/10.1053/j.gastro.2016.03.0

35

PMid: 27147121

17. Sivit CJ, Newman KD, Chandra RS. Visualization of enlarged mesenteric lymph nodes at US examination. Pediatric Radiology 1993; 23: 471-5. https://doi.org/10.1007/BF02012457 PMid: 8255656

18. Watanabe M, Ishii E, Hirowatari Y, et al. Evaluation of abdominal lymphadenopathy in children by ultrasonography. Pediatric Radiology 1997; 27: 860-4. https://doi.org/10.1007/s002470050256 PMid: 9361045

19. Macari M, Hines J, Balthazar E, Megibow A. Mesenteric adenitis: CT diagnosis of primary versus secondary causes, incidence, and clinical significance in pediatric and adult patients. American Journal of Roentgenology 2002; 178: 8538. https://doi.org/10.2214/ajr.178.4.1780853 PMid: 11906862

20. Karmazyn B, Werner EA, Rejaie B, Applegate KE. Mesenteric lymph nodes in children: what is normal? Pediatric Radiology 2005; 35: 774-7. https://doi.org/10.1007/s00247-005-14622 PMid: 15883829

21. Zhang, Liu Yingdong, Sun Hongguang, et al. Mesenteric lymph nodes in children with intussusception and its clinical significance $[\mathrm{J}]$. Journal of Clinical Medicine 2008; 12(3): 104-5. 
22. Chanchlani R. Clinical profile and management of mesenteric lymphadenitis in children - Our experience. International Journal of Orthopedics Traumatology and Surgical Sciences 2015; 1(1): 1-4.

23. Wever V. Abdominal ultrasonography in the diagnostic work-up in children with recurrent abdominal pain. European Journal of Pediatrics 1997; 156: 787-8. https://doi.org/10.1007/s004310050713

24. Jacob V, Krishna Kumar AS. Mesenteric lymphadenitis in children presenting with abdominal pain. Journal of Evolution of Medical and Dental Sciences 2013; 47(2): 9190-4.

https://doi.org/10.14260/jemds/1593 